\title{
Health and Lifestyle of University Freshmen: A Cross- Border Comparison among three Cities in China
}

\author{
Tony K C Yung ${ }^{1 *}$, Runsheng Jiang ${ }^{2}$ and Elvo K L Sou ${ }^{3}$ \\ ${ }^{1}$ Jockey Club School of Public Health and Primary Care, Faculty of Medicine, Hong Kong \\ ${ }^{2}$ School of Public Health, Kunming Medical University
}

${ }^{3}$ Student Affairs Office, University of Macau

*Corresponding author: Tony K C Yung, Jockey Club School of Public Health and Primary Care, Faculty of Medicine, Prince of

Wales Hospital, Shatin, New Territories, Hong Kong

\section{ARTICLE INFO}

Received: 魁 May 27, 2019

Published: 蔧 June 04, 2019

Citation: Tony K C Yung, Runsheng Jiang, Elvo K L S. Health and Lifestyle of University Freshmen: A Cross-Border Comparison among three Cities in China. Biomed J Sci \& Tech Res 18(4)-2019. BJSTR. MS.ID.003175.

Keywords: University freshmen; Lifestyles; Health status
ABSTRACT

Objectives: Limited work has been performed on intra-cultural, cross-societal variation among youth lifestyles and health status, and baseline data on university freshmen's health status are lacking. In the present study, we investigate the lifestyle patterns and health status of university freshmen studying in three Chinese cities.

Study design: Cross-sectional survey

Method: The study subjects were freshmen at the Chinese University of Hong Kong (CUHK), University of Macau (UM), and Kunming Medical University (KMU). Anonymous, self-administered questionnaires were distributed through a university admission package that was either mailed or distributed by hand.

Results: A total of 4233 freshmen completed the questionnaire. The response rates for CUHK, UM, and KMU were $80.8 \%, 65.0 \%$, and $100 \%$, respectively. CUHK $(20.4 \%)$ had the most overweight university freshmen and twice the proportion of overweight male students compared with KMU $(10.1 \%)(p<0.001)$. CUHK $(18.1 \%)$ had the smallest proportion of students who exercised regularly $(\mathrm{p}<0.001)$. UM $(23.7 \%)$ had the largest proportion of depressed freshmen $(\mathrm{p}=0.003)$. The proportion of alcohol binge drinkers in UM $(21.7 \%)$ was three times larger than that in CUHK $(6.0 \%)(\mathrm{p}<0.001)$. The proportion of current male smokers in KMU (24.8\%) was 24 times larger than that in CUHK $(1.0 \%)$ $(\mathrm{p}<0.001)$.

Conclusion: This study showed that the health status of youths varies across different societies even with the same culture. The study provides baseline health information to university administrators to prioritize students' health needs.

\section{Introduction}

Young people represent the future of families, communities, and nations. However, given that young people are considered to be at a relatively healthy stage of life, they are not viewed as a priority in health-promotion efforts worldwide [1]. Current research reveals that young people are engaged in unhealthy lifestyle activities, such as alcohol binge drinking, tobacco use, and physical inactivity [29]. These unhealthy choices are associated with negative health outcomes and the development of various chronic diseases in later life [10].
Aside from unhealthy lifestyle, the weight and mental state of young people are far from optimal. Studies have shown that obesity among young people is a global problem [5,11,12]. The prevalence of overweight youth varies between countries, but on the average, $12 \%$ to $32 \%$ of college students are overweight or obese. Globally, 20\% of adolescents suffer from various degrees of mental illness, with depression being the most common type of mental problem that affects college students [13]. Moreover, half of all adult mental disorders germinate in adolescence [14]. Mental 
health problems are aggravated by Internet misuse and addiction and have become a crucial social issue. Studies have revealed that $10 \%$ to $20 \%$ of adolescents are addicted to the Internet [15-16].

The severity of Internet addiction is associated with the degree of psychiatric symptoms, such as depression, obsessive compulsion, and interpersonal sensitivity [17]. Thus, pathologic Internet use is considered a new manifestation of adolescent depression [18].

The concept of "health-promoting university" was initially advocated by the World Health Organization as a setting-based approach for health promotion [19]. Universities can incorporate a health commitment into their organizational culture, structures, and practices to create supportive working, learning, and living environments that are conducive to a healthy life. However, relevant baseline data and evaluative research to access health promotion movements are lacking [20-21]. Therefore, an objective of the current study is to conduct a needs assessment so that health advocates can formulate corresponding health promotion strategies in university or college settings.

Previous studies have investigated health lifestyles and their association with socioeconomic status, culture, race, region, and locality [22-29]. However, little attention has been devoted to intracultural, cross-societal variations. How students' lifestyles and health status vary across different societies within the same cultural background remains unclear. Therefore, another objective of this work is to describe the patterns of selected unhealthy lifestyles and the health status of Chinese university freshmen studying in three cities in China.

\section{Materials and Methods}

\section{Participants}

University freshmen from three Chinese cities were recruited to participate in the study. The participants were from the Chinese University of Hong Kong (CUHK), University of Macau (UM), and Kunming Medical University (KMU). University freshmen who could read Chinese and respond to written questions in Chinese were eligible for the survey. Overseas students were excluded from the study due to the incompatibility of their past lifestyles and health practices.

\section{Procedures}

The data collection procedures in the three participating universities were similar, but slight adjustments were made according to the universities' respective semester schedules. Data collection was performed at the beginning (August to October) of the academic year. Participants were given an anonymous, self-administered questionnaire through a university admission package. They were asked to hand in the finished questionnaire at the health screening check that was compulsory for all freshmen. Written consent was obtained from each participant. The participants were told that their responses would not be documented in their university health records. Ethical approval was obtained from relevant committees in each participating university. Data were collected by CUHK, which was the coordination center of the overall survey. CUHK compiled the data from the three research sites and cleaned the data before analysis.

\section{Assessments}

\section{Basic Demographics}

In addition to gender and age, parents' education level and family income were used as an indicator of socioeconomic level. Given the considerable economic discrepancy between the two Special Administrative Regions (Hong Kong and Macau) and Kunming, the option for answering family income was adjusted accordingly. Furthermore, Kunming participants were asked if their families were from urban or rural areas.

\section{Body Weight Status}

The participants' body weight status was assessed using the body mass index (BMI), which was determined based on their body weight and height as measured during the health screening check. The participants were then classified as underweight $(<18.5$ $\left.\mathrm{kg} / \mathrm{m}^{2}\right)$, normal (18.5-22.9 kg/m²), and overweight (>23 kg/m $\left.{ }^{2}\right)$ according to WHO standards for Asians [30].

\section{Physical Activity Engagement}

Physical activity engagement involved vigorous exercises (those that make people breathe much harder than normal, such as football and swimming), moderate exercises (those that make people breathe harder than normal, such as fast walking and bicycling), and normal walking. The participants were asked how many days a week they participated in these types of physical activities for at least 30 minutes.

\section{Mental health}

As an indicator of mental health, depression was measured using the shortened version of the Center for Epidemiologic Studies Short Depression Scale (CES-D scale) [31]. The questionnaire comprised 10 questions that ask respondents to describe how they felt or behaved during the previous week in reference to the listed questions. The CES-D score ranges from 0 to 30. A high score indicates high frequency and number of depression symptoms. A score greater than or equal to 13 indicates mild or severe depression.

\section{Alcohol drinking}

The participants were asked if they ever drank alcohol, their frequency of alcohol drinking, and their experience with alcohol binge drinking (defined as having more than five alcoholic drinks in one occasion).

\section{Tobacco Use}

Tobacco use was assessed by asking if the participants ever smoked; if they answered yes, they were asked about their frequency of smoking. 


\section{Internet Use}

Apart from asking the participants about their experience in using the Internet, their potential pathological Internet use was also assessed using Chen's Internet Addiction Scale (CIAS) [32]. CIAS is a 26-item instrument developed in Taiwan, and it has been validated and used in various studies in Taiwan and Mainland China Respondents were requested to respond to questions, such as "I tried to reduce my online time but was not successful" and "I feel restless when the Internet connection is cut," by using the responses "very uncharacteristic," "uncharacteristic," "characteristic," or "very characteristic." Each question had one to four scores. A total score of 64 or above denoted pathological Internet use or addiction.

\section{Data analysis}

Data were analyzed with the Statistical Package for the Social Sciences (Version 21.0, SPSS Inc., Chicago, IL). For a descriptive presentation, the current study reported the proportions of students engaged in different lifestyle aspects and their health status. Pearson's chi-square test was utilized to test for statistically significant differences between locations. Given that gender strongly affects lifestyle and health status, the male and female students' responses were separated.

\section{Results}

\section{Demographics}

The current study solicited the participation of 4233 university freshmen. The respondents comprised 2567 (response rate of $80.8 \%$ ), 853 (response rate of 65\%), and 813 (response rate of $100 \%$ students from CUHK, UM, and KMU, respectively. KMU's perfect response rate was due to the researchers tracing every missing questionnaire from potential respondents. Table 1 shows the respondents' age and their parent's educational attainment. The average age of respondents was between 18 and 19. No obvious discrepancy was observed in the ages of the respondents from the three sites. The parents of the majority of the respondents attained junior or senior high school. About one-fourth of parents attained tertiary education. A small percentage of parents $(<5 \%)$ received no education or attended kindergarten only. Among the three sites, KMU had the smallest proportion (17.8\%) of respondents whose parents attained tertiary education.

Table 1: Age and parent's education attainment of the respondents.

\begin{tabular}{|c|c|c|c|c|c|c|c|c|c|c|c|c|}
\hline & \multicolumn{3}{|c|}{ CUHK } & \multicolumn{3}{|c|}{ UM } & \multicolumn{3}{|c|}{ KMU } & \multicolumn{3}{|c|}{ Overall } \\
\hline & $\begin{array}{c}\text { Male } \\
n=1169\end{array}$ & $\begin{array}{c}\text { Female } \\
n=1398\end{array}$ & $\begin{array}{c}\text { Total } \\
\mathbf{n}=2567\end{array}$ & $\begin{array}{c}\text { Male } \\
\mathrm{n}=317\end{array}$ & $\begin{array}{c}\text { Female } \\
n=536\end{array}$ & $\begin{array}{c}\text { Total } \\
\mathbf{n}=853\end{array}$ & $\begin{array}{c}\text { Male } \\
n=328\end{array}$ & $\begin{array}{c}\text { Female } \\
n=485\end{array}$ & $\begin{array}{c}\text { Total } \\
\mathbf{n}=\mathbf{8 1 3}\end{array}$ & $\begin{array}{c}\text { Male } \\
n=1814\end{array}$ & $\begin{array}{c}\text { Female } \\
n=2419\end{array}$ & $\begin{array}{c}\text { Total } \\
\mathbf{n}=4233\end{array}$ \\
\hline $\begin{array}{l}\text { Mean Age } \\
\text { (SD) }\end{array}$ & $\begin{array}{l}18.8 \\
(1.0)\end{array}$ & $\begin{array}{l}18.8 \\
(1.0)\end{array}$ & $\begin{array}{l}18.8 \\
(1.0)\end{array}$ & $\begin{array}{l}18.7 \\
(1.5)\end{array}$ & $\begin{array}{l}18.5 \\
(1.6)\end{array}$ & $\begin{array}{l}18.6 \\
(1.5)\end{array}$ & $\begin{array}{l}19.0 \\
(1.0)\end{array}$ & $\begin{array}{l}18.7 \\
(0.8)\end{array}$ & $\begin{array}{l}18.8 \\
(0.9)\end{array}$ & $\begin{array}{l}18.8 \\
(1.1)\end{array}$ & $\begin{array}{l}18.7 \\
(1.1)\end{array}$ & $\begin{array}{l}18.8 \\
(1.1)\end{array}$ \\
\hline $\begin{array}{c}\text { Parent } \\
\text { education^ } \\
(\%)\end{array}$ & & & & & & & & & & & & \\
\hline $\begin{array}{l}\text { No or kin- } \\
\text { dergarten }\end{array}$ & 1.1 & 0.9 & 1 & 0.6 & 0.2 & 0.4 & 4.9 & 2.3 & 3.3 & 1.7 & 1 & 1.3 \\
\hline Primary & 13.5 & 12.2 & 12.8 & 11.7 & 16 & 14.4 & 13.1 & 10.5 & 11.6 & 13.1 & 12.8 & 12.9 \\
\hline Junior High & 29.4 & 27.5 & 28.3 & 26.5 & 26.9 & 26.7 & 35.4 & 37.7 & 36.8 & 30 & 29.5 & 29.8 \\
\hline Senior High & 32.2 & 32.3 & 32.4 & 30.3 & 33.4 & 32.2 & 25.9 & 29.1 & 27.8 & 30.8 & 32.1 & 31.6 \\
\hline Tertiary & 23 & 26.3 & 24.8 & 29.7 & 23.1 & 25.6 & 18.6 & 17.3 & 17.8 & $23 . .4$ & 23.9 & 23.7 \\
\hline $\begin{array}{l}\text { Not appli- } \\
\text { cable / no } \\
\text { answer }\end{array}$ & 0.8 & 0.8 & 0.7 & 1.2 & 0.4 & 0.7 & 2.1 & 3.1 & 2.7 & 1 & 0.7 & 0.7 \\
\hline
\end{tabular}

$\wedge^{\wedge}$ Refers to the parent who has attained higher education

Table 2 presents the family income of the respondents from CUHK and UM. Generally, the respondents from Hong Kong had a higher family income than their Macau counterparts. A large proportion of the Hong Kong respondents (21.1\%) had a family income greater than $\mathrm{HK} \$ 30,000$. Meanwhile, $41 \%$ of the Macau respon- dents had a family income less than $\mathrm{HK} \$ 10,000$. The family income level of the Kunming respondents is shown in Table 3. Urban and rural Kunming respondents had a family income that was considerably lower than that of the Hong Kong and Macau respondents.

Table 2: Percentage of Hong Kong and Macau respondents with different family income levels.

\begin{tabular}{|c|c|c|c|c|c|c|}
\hline & \multicolumn{3}{|c}{ CUHK } & & UM \\
\cline { 2 - 7 } & Male n=1169 & Female $\mathbf{n = 1 3 9 8}$ & Total n=2567 & Male n=317 & Female n=536 & Total n=853 \\
\hline $\begin{array}{c}\text { Family monthly } \\
\text { income (\%) }\end{array}$ & & & & & & \\
\hline$<10,000$ & 26.5 & 24.9 & 25.6 & 44.2 & 39.2 & 41 \\
\hline $10,000-19,999$ & 34.4 & 34.2 & 34.3 & 34.7 & 36.6 & 35.9 \\
\hline
\end{tabular}




\begin{tabular}{|c|c|c|c|c|c|c|}
\hline $20,00-29,999$ & 17.3 & 15.5 & 16.3 & 12 & 15.7 & 14.3 \\
\hline$>30,000$ & 19.8 & 22.1 & 21.1 & 5.7 & 6.9 & 6.4 \\
\hline No answer & 2.1 & 3.4 & 2.8 & 3.5 & 1.7 & 2.3 \\
\hline
\end{tabular}

$\wedge^{\wedge}$ Family monthly income reported in HKD

Table 2: Percentage of Kunming respondents with different family income levels.

\begin{tabular}{|c|c|c|c|c|c|c|}
\hline & \multicolumn{6}{|c|}{ KMU } \\
\hline & \multicolumn{3}{|c|}{ Family lives in urban area (monthly income) } & \multicolumn{3}{|c|}{ Family lives in rural area (annual income) } \\
\hline & Male $n=120$ & Female $n=174$ & Total $n=294$ & Male $n=196$ & Female $\mathrm{n}=292$ & Total $n=488$ \\
\hline \multicolumn{7}{|c|}{ Family income $(\%)^{\wedge}$} \\
\hline$<1,499$ & 27.4 & 41.3 & 35.7 & 30.6 & 24.6 & 27 \\
\hline $1,500-2,999$ & 29.1 & 30.5 & 29.9 & 27.6 & 29.8 & 28.9 \\
\hline $3,000-4,999$ & 26.7 & 17.2 & 21.1 & 17.9 & 15.4 & 16.4 \\
\hline$>5,000$ & 15 & 8.1 & 10.9 & 20.9 & 29.5 & 26.1 \\
\hline No answer & 1.8 & 2.9 & 2.4 & 3 & 0.7 & 1.6 \\
\hline
\end{tabular}

Respondents who did not indicate their urban-rural residence were excluded

^Family monthly income reported in RMB (Currency at 2019 RMB:HKD $\cong 1: 1.14$ )

\section{Lifestyle and Health Status}

The percentages of respondents involved in various lifestyles and their health status are presented in Table 4. CUHK had the highest percentage of overweight students $(13.7 \%)(\mathrm{p}<0.001)$, whereas KMU had the lowest percentage (9.3\%). Further analysis showed that for male students, CUHK (20.4\%) and UM (19.9\%) had twice the proportion of overweight students compared with KMU $(10.1 \%)(p<0.001)$. For females, a significantly larger proportion of underweight students was found in KMU (8.9\%) and CUHK (8.0\%) than in UM $(7.1 \%)(p<0.001)$. Comparison of the three sites in terms of physical exercise engagement showed that KMU had the highest percentage $(46.2 \%)$ of students participating in regular vigorous exercise $(\mathrm{p}<0.001)$. CUHK had the lowest percentage (18.1\%) of students who vigorously exercised regularly. Further analysis by gender indicated that males and females exhibited the same pattern, that is, KMU students of both genders exercised more vigorously. The proportion of students engaged in moderate exercise in the three sites displayed the same pattern of vigorous exercise $(p<0.001)$. However, walking did not show a significant difference in the three sites.

Table 3: Percentage of respondents in various lifestyles and health status (\%).

\begin{tabular}{|c|c|c|c|c|c|c|c|c|c|c|c|c|c|c|c|}
\hline & \multicolumn{3}{|c|}{ CUHK } & \multicolumn{3}{|c|}{ UM } & \multicolumn{3}{|c|}{ KMU } & \multicolumn{3}{|c|}{ Overall } & \multicolumn{3}{|c|}{$p$ values } \\
\hline & $\begin{array}{c}\text { Male } \\
n=1169\end{array}$ & $\begin{array}{l}\text { Female } \\
n=1398\end{array}$ & $\begin{array}{c}\text { Total } \\
n=2567\end{array}$ & $\begin{array}{c}\text { Male } \\
\mathbf{n}=317\end{array}$ & $\begin{array}{c}\text { Female } \\
n=536\end{array}$ & $\begin{array}{c}\text { Total } \\
\mathbf{n}=853\end{array}$ & $\begin{array}{c}\text { Male } \\
\mathrm{n}=328\end{array}$ & $\begin{array}{l}\text { Female } \\
n=485\end{array}$ & $\begin{array}{c}\text { Total } \\
\mathbf{n}=\mathbf{8 1 3}\end{array}$ & $\begin{array}{c}\text { Male } \\
n=1814\end{array}$ & $\begin{array}{l}\text { Female } \\
n=2419\end{array}$ & $\begin{array}{c}\text { Total } \\
n=4233\end{array}$ & $\begin{array}{c}\text { Males } \\
\text { across } \\
\text { location }\end{array}$ & $\begin{array}{c}\text { Female } \\
\text { across } \\
\text { location }\end{array}$ & $\begin{array}{c}\text { Total } \\
\text { across } \\
\text { location }\end{array}$ \\
\hline $\begin{array}{c}\text { Body weight } \\
\text { status }\end{array}$ & & & & & & & & & & & & & $<0.001$ & $<0.001$ & $<0.001$ \\
\hline $\begin{array}{c}\text { BMI < 18.5 } \\
\text { (Underweight) }\end{array}$ & 21 & 32.8 & 27.4 & 19.6 & 38.2 & 31.3 & 20.1 & 24.1 & 22.5 & 20.6 & 32.2 & 27.3 & & & \\
\hline $\begin{array}{c}\text { BMI 18.5-22.9 } \\
\text { (Normal) }\end{array}$ & 57.7 & 57.9 & 57.9 & 54.9 & 51.7 & 52.9 & 68.9 & 65.6 & 66.9 & 59.3 & 58.1 & 58.6 & & & \\
\hline $\begin{array}{c}\text { BMI } \geq 23 \\
\text { (Overweight) }\end{array}$ & 20.4 & 8 & 13.7 & 19.9 & 7.1 & 11.8 & 10.1 & 8.9 & 9.3 & 18.5 & 8 & 12.5 & & & \\
\hline No answer & 0.9 & 1.3 & 1 & 5.6 & 3 & 4 & 0.9 & 0.4 & 1.3 & 1.6 & 1.7 & 1.6 & & & \\
\hline \multicolumn{16}{|l|}{$\begin{array}{c}\text { Physical activity } \\
\text { engagement }\end{array}$} \\
\hline $\begin{array}{l}\text { Vigorous Ex } \\
>3 / w k\end{array}$ & 23.9 & 13.4 & 18.1 & 39.4 & 20.9 & 27.8 & 56.1 & 39.6 & 46.2 & 32.4 & 20.3 & 25.5 & $<0.001$ & $<0.001$ & $<0.001$ \\
\hline $\begin{array}{c}\text { Moderate Ex } \\
>3 / w k\end{array}$ & 35.5 & 24.7 & 29.6 & 39.4 & 30 & 33.5 & 54 & 48.7 & 50.8 & 39.5 & 30.7 & 34.5 & $<0.001$ & $<0.001$ & $<0.001$ \\
\hline Walking $>3 /$ wk & 77.3 & 77.6 & 77.4 & 76 & 74.8 & 75.3 & 71.6 & 81.9 & 77.7 & 76.1 & 77.8 & 77.1 & 0.1 & 0.02 & 0.37 \\
\hline Mental health & & & & & & & & & & & & & 0.48 & 0.03 & 0.03 \\
\hline $\begin{array}{c}\text { CES-D scores } \\
<13\end{array}$ & 80.3 & 77.6 & 78.9 & 76.3 & 72 & 73.6 & 75.9 & 80.2 & 78.5 & 78.8 & 76.9 & 77.7 & & & \\
\hline $\begin{array}{l}\text { CES-D scores } \\
\quad \geq 13\end{array}$ & 18.9 & 21.7 & 20.4 & 21.5 & 25 & 23.7 & 19.8 & 18.8 & 19.2 & 19.5 & 21.8 & 20.8 & & & \\
\hline
\end{tabular}




\begin{tabular}{|c|c|c|c|c|c|c|c|c|c|c|c|c|c|c|c|}
\hline No answer & 0.8 & 0.7 & 0.7 & 2.2 & 3 & 2.7 & 4.3 & 1 & 2.3 & 1.7 & 1.3 & 1.4 & & & \\
\hline \multicolumn{16}{|l|}{$\begin{array}{l}\text { Alcohol } \\
\text { drinking }\end{array}$} \\
\hline Ever drink & 70.1 & 59.6 & 64.4 & 71.4 & 64.3 & 66.9 & 76.3 & 55.5 & 63.5 & 71.4 & 59.8 & 64.8 & 0.32 & 0.12 & 0.55 \\
\hline Current drinker & 64.8 & 47.7 & 55.5 & 64.6 & 58.1 & 60.5 & 69.4 & 40.1 & 51.5 & 65.6 & 48.5 & 55.8 & 0.65 & $<0.001$ & 0.003 \\
\hline $\begin{array}{c}\text { Drink at least } \\
1 / \text { week }\end{array}$ & 2.1 & 0.4 & 1.2 & 7.5 & 0.7 & 3.2 & 1.3 & 0 & 0.5 & 2.9 & 0.4 & 1.5 & $<0.001$ & 0.48 & 0.003 \\
\hline $\begin{array}{l}\text { Binge drink in } \\
\text { previous month }\end{array}$ & 9.8 & 2.8 & 6 & 33.5 & 14.8 & 21.7 & 26.8 & 6.1 & 14.1 & 17 & 6.2 & 10.8 & $<0.001$ & $<0.001$ & $<0.001$ \\
\hline \multicolumn{16}{|l|}{ Tobacco use } \\
\hline Ever smoke & 2.1 & 0.7 & 1.3 & 11.2 & 5.4 & 7.5 & 31.8 & 1.6 & 13.4 & 8.9 & 2 & 4.9 & $<0.001$ & $<0.001$ & $<0.001$ \\
\hline Current smoker & 1 & 0.3 & 0.6 & 6.8 & 3.6 & 4.8 & 24.8 & 1.2 & 10.4 & 6.2 & 1.2 & 3.4 & $<0.001$ & $<0.001$ & $<0.001$ \\
\hline $\begin{array}{c}<1 \text { cigarette/ } \\
\text { day }\end{array}$ & 1 & 0.3 & 0.6 & 0.3 & 1.8 & 2.7 & 15.9 & 1.2 & 6.9 & 4.2 & 0.8 & 2.3 & & & \\
\hline $\begin{array}{c}\text { 1-9 cigarettes/ } \\
\text { day }\end{array}$ & 0 & 0 & 0 & 0 & 0 & 0 & 7 & 0 & 2.7 & 1.2 & 0 & 0.5 & & & \\
\hline $\begin{array}{l}\text { Q10 cigarettes/ } \\
\text { day }\end{array}$ & 0 & 0 & 0 & 0 & 0 & 0 & 0.6 & 0 & 0.2 & 0.1 & 0 & 0 & & & \\
\hline $\begin{array}{l}\text { Did not indicate } \\
\text { frequency }\end{array}$ & 0 & 0 & 0 & 6.5 & 1.8 & 2.1 & 1.3 & 0 & 0.6 & 0.7 & 0.4 & 0.6 & & & \\
\hline \multicolumn{16}{|l|}{ Internet use } \\
\hline $\begin{array}{l}\text { Pathological } \\
\text { Internet Use }\end{array}$ & 5.5 & 5 & 5.2 & 9.7 & 8.3 & 8.8 & 1.3 & 0.9 & 1.1 & 5.5 & 4.9 & 5.2 & 0.006 & 0.002 & $<0.001$ \\
\hline
\end{tabular}

The mental health status of the respondents varied between the two genders. Specifically, for males, no significant difference was observed in the percentage of students who had mild or severe depression (CES-D score $\geq 13$ ). For females, UM showed a higher percentage $(25 \%)$ of students who had mild or severe depression compared with CUHK (21.7\%) and KMU (18.8\%) (p=0.03). When both genders are combined, Macau still showed a significantly high percentage $(23.7 \%)$ of students suffering from mild to severe depression ( $\mathrm{p}=0.03)$. Hong Kong (20.4\%) and Kunming (19.2\%) had similar proportions of depressive students. Among the three research sites, Macau had the highest percentage of current female drinkers $(58.1 \%)(p<0.001)$. The habit of binge drinking was common among students in Macau. For both genders, the largest proportion of students who binge drank (male 33.5\%; female $14.8 \%)$ in the month prior to the survey was in Macau $(\mathrm{p}<0.001)$. Macau's combined figure for binge drinking (21.7\%) was more than three times that of Hong Kong (6.0\%).

The smoking habits in the three research sites showed a large discrepancy. The proportion of current male smokers in KMU (15.9\%) was significantly higher than that in CUHK $(1.0 \%)$ and UM $(0.3 \%)(p<0.001)$. For females, however, Macau had the largest proportion of students (3.6\%) who were current smokers. In terms of Internet addiction, Macau had the largest proportion of students (8.8\%) suffering from pathological Internet use under CIAS ( $p<0.001)$. By contrast, Kunming had the lowest rate $(1.1 \%)$ of Internet-addicted students. This pattern was consistent for males $(p=0.006)$ and females $(p=0.002)$.

\section{Discussion}

The current study revealed that the overall percentage of overweight students was $12.5 \%$. This result is in line with those of previous studies that used Asian university freshmen as investigation subjects [12,33]. Nevertheless, a very large difference in the overweight percentage was observed among the three cities. For instance, Hong Kong and Macau males had a double overweight percentage compared with Kunming males. This result may be explained by the lack of physical activity. Adding to this cause is the massive influence of westernized diet and fast food culture on the two Special Administrative Regions over the past decades. The body weight status of the female students showed less variation among the three cities. Despite this result, many females (overall, 32.2\%) were underweight, which is indicative of another potential health issue. Given that the three research sites are not economically disadvantaged regions and food supply is abundant, the abovementioned issue reflects a possible misconception of the perception of healthy weight status among female students. Several studies have emphasized that restrictive slimming behaviors are common among female university students and that the percentage of university students who perceive they are overweight or obese is higher than the percentage of students who are actually in these weight categories [34]. This finding indicates that resources allocated to tackle weight problems should consider the problem of over-nutrition and the irrational pursuit of a slim body, which has been demonstrated to be a predictor of eating pathology and psychological problems among university students [35]. 
Hong Kong has an extremely low rate of physical exercise participation compared with the two other sites. To a certain extent, this condition explains why a large proportion of male students in Hong Kong are overweight. Abdullah et al. [2] reported that "no time" and "no interest" are the two main reasons for the physical inactivity of Hong Kong university students. This finding reveals the need to reinforce physical activity as a priority due to its relevance to individual health.

In the present study, $20.8 \%$ of the students suffered from depressive symptoms. This figure is comparable to those in previous similar studies [36,37] and indicates that the general mental health status of our respondents was far from optimal. Reversal of the current situation is vital in preventing further deterioration of university students' mental health because the academic requirement is a significant source of pressure.

Comparison of the three research sites revealed that Macau had the largest proportion of students suffering from depression. Such a phenomenon is difficult to explain because of the lack of relevant literature. A possible reason is that the alcohol consumption of Macau students is more problematic than that of students in the two other sites. A larger proportion of depressed students is expected because alcohol consumption has been linked with depression symptoms according to a review of empirical findings [38].

Nearly $25 \%$ of the male respondents from KMU were current smokers. This figure is substantially higher than the smoking rate in many western countries. $[9,42,43]$ Previous studies have revealed that smoking is associated with depression symptoms among university students [44]. In view of its strong association with lung cancer and other chronic respiratory diseases and the addictive nature of tobacco smoking, relevant intervention aimed at reducing the smoking rate in the university setting is crucial.

In our study, the rate of Internet addiction was 5.2\%, with both genders showing similar prevalence. Previous studies have reported that the rate of Internet addiction or pathological use among adolescent's ranges from $4 \%$ to $18 \%$. Making a reasonable comparison is difficult because these studies used different scales to assess Internet addiction. However, excessive Internet use has been associated with academic and social problems. Pathological Internet use causes low self-esteem and social disinhibition [44]. The rate of Internet addiction is likely to continue rising because Internet use is expected to increase during college. Hence, healthy use of the Internet should be reinforced through appropriate channels as soon as possible.

The primary strength of the present study is the adoption of a large sample size that covers students of unselected disciplines, and hence a representative sample coming from the three research sites. However, this study has limitations. First, the subjects were university freshmen. Therefore, the results only reflect geographical differences in lifestyle and health status but do not imply any effect attributable to university life. Further study needs to be performed to investigate how university life affects a student's lifestyle and health status. Second, although Kunming is the capital city of Yunnan Province and is undergoing rapid development, a substantial economic discrepancy still exists when it is compared with Macau and Hong Kong. Socioeconomic status influences lifestyle formation [27]. Interpretation of the results needs to consider such an influence. Third, due to limited resources, this study targeted and reported only on six areas about freshmen's health status and lifestyles.

To conclude, the three universities had unique concerns about the health of their freshmen. Several of the lifestyles and health statuses were inter-related. The health status of youths varied across different societies even with the same cultural background. This result provides valuable hints to health intervention planners when they perform their work. Moreover, the study supplies baseline health information that can be used by health administrators in colleges and universities to prioritize students' health needs.

\section{Acknowledgement}

This study was supported by Li Ka Shing Foundation. The authors thank Ruochen, Minjung, Sukaina, Dharshika and Preety for their assistance to this study.

\section{References}

1. (1998) World Health Organization. Adolescent health and development: The second decade. Manila: World Health Organization, Regional Office for the Western Pacific Region.

2. Abdullah ASM, Wong CM, Yam HK, Fielding R (2005) Factors related to non-participation in physical activity among the students in Hong Kong. Int J Sports Med 26(7): 611-615.

3. Gfroerer JC, Greenblatt JC, Wright DA (1997) Substance use in the US college-age population: differences according to educational status and living arrangement. Am J Public Health 87(1): 62-65.

4. Griffiths S, Lau JTF, Chow JKW, Lee SS, Kan PYMY, et al. (2006) Alcohol use among entrants to a Hong Kong University. Alcohol 41(5): 560-565.

5. Huang TTK, Harris KJ, Lee RE, Nazir N, Born W, et al. (2003) Assessing overweight, obesity, diet, and physical activity in college students. J Am Coll Health 52(2): 83-86.

6. Ku PW, Fox KR, McKenna J, Peng TL (2006) Prevalence of leisure-time physical activity in Taiwanese adults: results of four national surveys. 2000-2004. Prev Med 43(6): 454-457.

7. Li X, Fang X, Stanton B, Feigelman S, Dong Q (1996) The rate and pattern of alcohol consumption among Chinese adolescents. J Adolesc Health 19(5): 353-361.

8. Liu GR (1997) An investigation of adolescent health from China. J Adolesc Health 20(4): 306-308.

9. Thompson B, Coronado G, Chen L, Thompson LA, Halperin A, et al. (2007) Prevalence and characteristics of smokers at 30 Pacific Northwest colleges and universities. Nicotine Tob Res 9(3): 429-438.

10. Elliott DS (1993) Health-enhancing and health-compromising lifestyles. In: Millstein SG, Pertersen AC, Nightingale EO, (Eds.), Promoting the health of adolescents: New directions for the twenty-first century. New York: Oxford University Press pp. 119-145.

11. Al Isa AN (1999) Obesity among Kuwait University students: an explorative study. J R Soc Health 119(4): 223-227.

12. Nojomi M, Najamabadi S (2006) Obesity among university students, Tehran, Iran. Asia Pac J Clin Nutr 15(4): 516-520. 
13. Arehart Treichel J (2002) Mental Illness on Rise on College Campuses. Psychiatr News 37(6): 6-38.

14. Belfer ML (2008) Child and adolescent mental disorders: The magnitude of the problem across the globe. J Child Psychol Psychiatry 49(3): 226236.

15. Shek DTL, Tang VMY, Lo CY (2008) Internet addiction in Chinese adolescents in Hong Kong: assessment, profiles, and psychosocial correlates. Scientific World Journal 8: 776-787.

16. Wu HR, Zhu KJ (2004) Path analysis on related factors causing internet addiction disorder in college students. Chin J Public Health 20: 13631364.

17. Jang KS, Hwang SY, Choi JY (2008) Internet addiction and psychiatric symptoms among Korean adolescents. J Sch Health 78(3): 165-171.

18. Cao F, Su L, Liu T, Gao X (2007) The relationship between impulsivity and Internet addiction in a sample of Chinese adolescents. Eur Psychiatry 22(7): 466-471.

19. Tsouros AD, Dowding G, Thompson J, Dooris M, et al. (1998) Health Promoting Universities: Concept, experience and framework for action. World Health Organization: The Regional Office for Europe, Copenhagen.

20. Lee S (2002) Health promoting university initiative in Hong Kong. Promot Educ Suppl 1: 15.

21. Whitehead D (2004) The Health Promoting University (HPU): the role and function of nursing. Nurse Educ Today 24(6): 466-472.

22. Chen MY, James K, Wang EK (2007) Comparison of health-promoting behavior between Taiwanese and American adolescents: a crosssectional questionnaire survey. Int J Nurs Stud 44(1): 59-69.

23. Haddad LG, Al MaAitah RM, Umlauf MG (1999) Health Promotion Behaviors among Jordanians. Int Q Community Health Educ 18(2): 223236.

24. Johnson RL (2005) Gender differences in health-promoting lifestyles of African Americans. Public Health Nurs 22(2): 130-137.

25. Lee A, Mittelmark MB (2002) Health promotion and health education in China: priority area for the IUHPE. Promot Educ Suppl 1: 6-7.

26. Quintero MA, Torres ICS (2005) Lifestyle-related beliefs of young LatinAmericans. Psicologia Conductual 13(1): 19-36.

27. Shi Z, Lien N, Kumar BN, Holmboe Ottesen G (2005) Socio-demographic differences in food habits and preferences of school adolescents in Jiangsu Province, China. Eur J Clin Nutr 59(12): 1439-1448.

28. Stahl T, Rutten A, Nutbeam D, Bauman A, Kannas L, et al. (2001) The importance of the social environment for physically active lifestyle-results from an international study. Soc Sci Med 52(1): 1-10.

29. Uitenbroek DG, Kerekovska A, Festchieva N (1996) Health lifestyle behaviour and socio-demographic characteristics. A study of Varna, Glasgow and Edinburgh. Soc Sci Med 43(3): 367-377.

30. (2000) World Health Organization, the Regional Office for the Western Pacific, The International Association for the Study of Obesity, The International Obesity Task Force. The Asia-Pacific perspective: Redefining obesity and its treatment.

\section{ISSN: 2574-1241}

\section{DOI: 10.26717/BJSTR.2019.18.003175}

Tony K C Yung. Biomed J Sci \& Tech Res

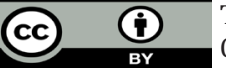

This work is licensed under Creative Commons Attribution 4.0 License

Submission Link: https://biomedres.us/submit-manuscript.php
31. Andresen EM, Malmgren JA, Carter WB, Patrick DL (1994) Screening for depression in well older adults: evaluation of a short form of the CES-D (Center for Epidemiologic Studies Depression Scale). Am J Prev Med 10(2): 77-84

32. Ko CH, Yen JY, Yen CF, Chen CC, Yen CN, et al. (2005) Screening for Internet addiction: an empirical study on cut-off points for the Chen Internet Addiction Scale. Kaohsiung J Med Sci 21(12): 545-551.

33. Yen SL, Chiu TY, Lin YC, Lee YC, Lee LT, et al. (2008) Obesity and hepatitis $\mathrm{B}$ infection are associated with increased risk of metabolic syndrome in university freshmen. Int J Obes (Lond) 32(3): 474-480.

34. Wong Y, Huang YC (1999) Obesity concerns, weight satisfaction and characteristics of female dieters: a study on female Taiwanese college students. J Am Coll Nutr 18(2): 194-200.

35. Liebman M, Cameron BA, Carson DK, Brown DM, Meyer SS (2001) Dietary fat reduction behaviors in college students: relationship to dieting status, gender and key psychosocial variables. Appetite 36(1): 51-56.

36. Galaif ER, Sussman S, Newcomb MD, Locke TF (2007) Suicidality, depression, and alcohol use among adolescents: a review of empirical findings. Int J Adolesc Med Health 19(1): 27-35.

37. Bostanci M, Ozdel O, Oguzhanoglu NK, Ozdel L, Ergin A, et al. (2005) Depressive symptomatology among university students in Denizli, Turkey: prevalence and sociodemographic correlates. Croat Med J 46(1): 96-100.

38. Mikolajczyk RT, Maxwell AE, El Ansari W, Naydenova V, Stock C, et al. (2008) Prevalence of depressive symptoms in university students from Germany, Denmark, Poland and Bulgaria. Soc Psychiatry Psychiatr Epidemiol 43(2): 105-112.

39. Carroll SL, Lee RE, Kaur H, Harris KJ, Strother ML, et al. (2006) Smoking, weight loss intention and obesity-promoting behaviors in college students. J Am Coll Nutr 25(4): 348-353.

40. Cilliers J, Senekal M, Kunneke E (2006) The association between the body mass index of first-year female university students and their weight-related perceptions and practices, psychological health, physical activity and other physical health indicators. Public Health Nutr 9(2): 234-243.

41. Kenney BA, Holahan CJ (2008) Depressive symptoms and cigarette smoking in a college sample. J Am Coll Health 56(4): 409-414.

42. Vogel JS, Hurford DP, Smith JV, Cole A (2003) The relationship between depression and smoking in adolescents. Adolescence 38(149): 57-74.

43. Ko CH, Yen JY, Yen CF, Lin HC, Yang MJ (2007) Factors predictive for incidence and remission of internet addiction in young adolescents: a prospective study. Cyberpsychol Behav 10(4): 545-551.

44. Niemz K, Griffiths M, Banyard P (2005) Prevalence of pathological Internet use among university students and correlations with selfesteem, the General Health Questionnaire (GHQ), and disinhibition. Cyberpsychol Behav 8(6): 562-570.

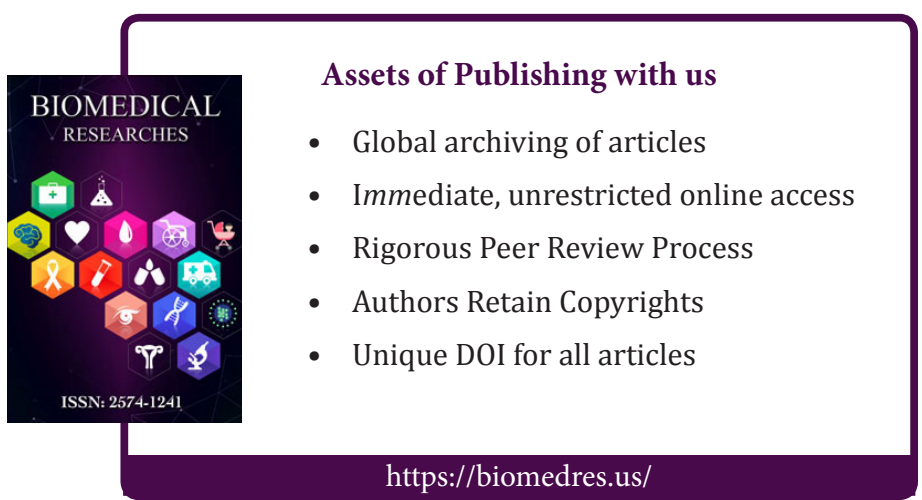

